\title{
Pesticides in Fresh Potatoes Sold in Farmers' Markets in Alberta, Canada
}

\author{
Thomas S. Thompson • Rick Dimock • \\ Robert W. Bradbury $\cdot$ Richard Rieve $\cdot$ \\ Mark Fehr
}

Received: 25 May 2011/ Accepted: 2 September 2011/Published online: 10 September 2011

(C) Springer Science+Business Media, LLC 2011

\begin{abstract}
Fresh potatoes (228 samples) from 34 farmers' markets in Alberta were analyzed for 29 pesticides. Residues of three different pesticides were found in the samples tested with chlorpropham being most frequently detected $(\mathrm{n}=13)$ at concentrations ranging from 15 to 7,600 $\mu \mathrm{g} \mathrm{kg}^{-1}$. Azoxystrobin $(\mathrm{n}=11)$ and imidacloprid $(\mathrm{n}=8)$ were found at concentrations ranging from 0.6 to 5.1 and 15-31 $\mathrm{g} \mathrm{kg}^{-1}$, respectively. All pesticide concentrations were below Canadian maximum residue limits as established for potatoes. No pesticide residues were detected in 23 potato samples obtained from certified organic farmers.
\end{abstract}

Keywords Potato $\cdot$ Pesticide $\cdot$ LC-MS/MS .

Farmers' market

In recent years farmers' markets have gained popularity for a variety of reasons. One factor is the appeal and availability of fresh, locally produced fruits and vegetables as opposed to produce that has been grown in other regions and shipped over long distances to supermarkets. The ability of the consumer to interact directly with the farmer

T. S. Thompson ( $₫)$

Alberta Agriculture and Rural Development, Food Safety and Animal Health Division, Agri-Food Laboratories Branch, 6909-116th Street, Edmonton, AB T6H 4P2, Canada

e-mail: tom.thompson@gov.ab.ca

R. Dimock · R. Rieve

Capital Health, Public Health Division, Environmental Public

Health Services, 10216-124 Street, Edmonton, AB T5N 4A3,

Canada

R. W. Bradbury · M. Fehr

Calgary Health Region, 1509 Centre Street SW, Calgary

AB T2G 2E6, Canada permits the purchaser the opportunity to inquire about the types of agricultural practices employed in the production of the fruits and vegetables. The application of pesticides in agriculture continues to be a major food safety issue with consumers. Many vendors in farmers' markets promote their products as being organic or produced without the use of pesticides. Farmers' markets in the province of Alberta generate annual sales of approximately $\$ 400$ million with over 100 markets in operation (Alberta Agriculture and Rural Development 2010). A variety of agri-food products including fresh fruits and vegetables are sold at many of these farmers' markets.

Government agencies such as the Canadian Food Inspection Agency (CFIA) and the United States Department of Agriculture (USDA) have established national pesticide residue monitoring programs for agri-food commodities. Data included in their annual reports have been summarized to provide a general overview of chemical residues on a nationwide basis. To obtain a more detailed snapshot of pesticide residues in potatoes produced in Alberta and sold at farmers' markets in the province, a collaborative study was carried out by regional health authorities for the two major urban centres in Alberta (Calgary and Edmonton) and the Government of Alberta's Food Safety and Animal Health Division (FSAHD).

The pesticides selected for inclusion in this study were chosen on the basis of their potential use in potato crops in Alberta. As a result of the diverse nature of the targeted pesticides, a multiresidue analytical method was devised. Hyphenated instrumental techniques that combine chromatographic separation with mass spectrometric detection capabilities are routinely employed in many laboratories worldwide. Liquid chromatography-mass spectrometry (LC-MS) has been used for the simultaneous determination of multiresidue pesticides in various types of produce 
including potatoes (Okihashi et al. 2002; Liu et al. 2005). Liquid chromatography coupled to tandem mass spectrometry (LC-MS/MS) provides increased selectivity and sensitivity relative to LC-MS. This technique has been used for the determination of various pesticide residues in potatoes (Hogenboom et al. 2000; Granby et al. 2004; Jansson et al. 2004; Ortelli et al. 2004; Leandro et al. 2007; Wang et al. 2010). Potato samples obtained from farmers' markets located near the two largest urban centres in Alberta (Calgary and Edmonton) were analyzed for 29 pesticides using LC-MS/MS.

\section{Materials and Methods}

Pesticide standards and triphenylphosphate, which was used as an internal standard in the analytical method, were purchased from Sigma-Aldrich Canada Limited (Oakville, ON, Canada). Individual stock standard solutions of each compound were prepared in acetonitrile at a concentration of $1,000 \mu \mathrm{g} \mathrm{mL}^{-1}$. These stock solutions were used to generate working solutions for the subsequent preparation of matrix-matched calibration standards. HPLC grade acetonitrile employed for sample extraction and chromatographic separation was obtained from Caledon Laboratories Limited (Georgetown, ON, Canada). Reagent water was prepared using a NANOpure Diamond model D11931 reverse osmosis system from Barnstead International (Dubuque, IA, USA). Analytical grade formic acid (98\%$100 \%$ ) was purchased from EM Science (Gibbstown, NJ, USA).

Potato samples were purchased by Calgary and Edmonton regional health personnel at farmers' markets located in or near the two cities. Samples were delivered directly to the laboratory or refrigerated prior to shipment in a chilled cooler the following day. Potato samples were thoroughly blended using a food processor and $2.5 \mathrm{~g}$ portions of the homogenized material were weighed into centrifuge tubes. The tubes were stored in a freezer at $-20^{\circ} \mathrm{C}$ until analyzed.

Each batch of potato samples was processed with a set of matrix-matched calibrators prepared by fortifying a series of homogenized blank potato samples with working solutions containing all 29 pesticides. The concentrations of the matrix-matched standards were 5, 10, 50, 100, 200, 400 and $500 \mu \mathrm{g} \mathrm{kg}^{-1}$ of each analyte. Three additional matrix-matched standards were also prepared where the concentration of chlorpropham was 2,000, 4,000 and $8,000 \mu \mathrm{g} \mathrm{kg}^{-1}$. A negative control sample was processed with every batch of samples. One duplicate sample from the batch was chosen at random and fortified with the equivalent of $50 \mu \mathrm{g} \mathrm{kg}^{-1}$ of each pesticide. All potato samples including controls, spiked duplicates and matrix-matched calibrators were fortified with $0.025 \mathrm{~mL}$ of a working solution containing $40 \mu \mathrm{g} \mathrm{mL}^{-1}$ of triphenylphosphate in acetonitrile. The samples were extracted with $2.5 \mathrm{~mL}$ of acetonitrile by mixing on a mechanical shaker for $30 \mathrm{~min}$. The tubes were centrifuged and an aliquot of the resulting extract was passed through a $0.2 \mu \mathrm{m}$ syringe filter into an LC autosampler vial.

Chromatographic separations were performed using a Waters Acquity ultra performance liquid chromatography system (Milford, MA, USA) equipped with an Agilent Technologies Zorbax Eclipse Plus C18 column $(2.1 \times$ $100 \mathrm{~mm}$ with $1.8 \mu \mathrm{m}$ particles). A binary gradient elution program with mobile phase $\mathrm{A}=0.1 \%(\mathrm{v} / \mathrm{v})$ formic acid in water and mobile phase $\mathrm{B}=0.1 \%(\mathrm{v} / \mathrm{v})$ formic acid in acetonitrile was utilized. The initial step of the gradient had the mobile phase composition increasing from $10 \%$ to $100 \%$ B over $5 \mathrm{~min}$ at a constant flow rate of $0.3 \mathrm{~mL} \mathrm{~min}^{-1}$. The flow rate was subsequently increased to $0.6 \mathrm{~mL} \mathrm{~min}^{-1}$ and held for $3 \mathrm{~min}$. Finally, the mobile phase composition and flow rate were returned to the initial conditions with an equilibration time of $3 \mathrm{~min}$ given between injections. The LC column was maintained at $40^{\circ} \mathrm{C}$ and an injection volume of $20 \mu \mathrm{L}$ with a filled sample loop was used for all analyses.

A Micromass Quattro Premier tandem quadrupole MS/ MS system (Manchester, UK) was used for the detection of pesticide residues. Positive electrospray ionization (ESI) was employed for all compounds with the exception of fludioxonil which was analyzed in the negative ion mode. Automatic switching of the ion optics polarity during the analytical run permitted the simultaneous determination of all target pesticides. The MS/MS was operated in the selected reaction monitoring (SRM) mode with two product-precursor ion transitions per compound as indicated in Table 1. The dwell time for each SRM transition was $5 \mathrm{~ms}$. The ion source and probe desolvation temperatures were set at 120 and $350^{\circ} \mathrm{C}$ respectively. The ESI capillary voltage was switched between $+3.5 \mathrm{kV}$ for the positive ion mode and $-3.0 \mathrm{kV}$ in the negative ion mode. Nitrogen flow rates for desolvation, nebulizer and cone gases were 600, 90 and $50 \mathrm{~L} \mathrm{~h}^{-1}$ respectively. The collision cell was filled with argon gas at a pressure of $3.3 \times 10^{-3}$ mbar.

The analytical method was validated by analyzing a set of blank potato samples fortified with all 29 pesticides. Four different sources of potato samples were selected and sets of three replicates of each were spiked with 50 and $300 \mu \mathrm{g} \mathrm{kg}^{-1}$ of the target pesticides. The matrix-matched calibrators were generated using a fifth pooled blank potato sample.

\section{Results and Discussion}

The proposed analytical method was intended for use in screening for pesticide residues in potato samples and 
Table 1 MS/MS parameters for the determination of pesticides in potatoes
${ }^{a}$ Collision energy $(\mathrm{eV})$ given in parentheses

\begin{tabular}{|c|c|c|c|}
\hline Compound & Cone voltage (V) & Quantitation SRM $^{\mathrm{a}}$ & Confirmation SRM ${ }^{\mathrm{a}}$ \\
\hline Acetamiprid & 30 & $223>126(21)$ & $223>90(32)$ \\
\hline Azinphos-methyl & 15 & $318>132(16)$ & $318>77(36)$ \\
\hline Azoxystrobin & 25 & $404>372(14)$ & $404>344(24)$ \\
\hline Boscalid & 30 & $343>140(20)$ & $343>307(20)$ \\
\hline Carbaryl & 17 & $202>145(10)$ & $202>127(26)$ \\
\hline Carbofuran & 25 & $222>165(12)$ & $222>123(20)$ \\
\hline Chlorpropham & 18 & $214>172(8)$ & $214>154(16)$ \\
\hline Cymoxanil & 15 & $199>128(8)$ & $199>111(18)$ \\
\hline Diazinon & 33 & $305>169(20)$ & $305>153(20)$ \\
\hline Dimethoate & 20 & $230>199(8)$ & $230>125(20)$ \\
\hline Dimethomorph & 40 & $388>301(20)$ & $388>165(30)$ \\
\hline EPTC & 25 & $190>128(10)$ & $190>86(12)$ \\
\hline Fenamidone & 25 & $312>92(24)$ & $312>236(14)$ \\
\hline Fluazifop-butyl & 33 & $384>282(20)$ & $384>328(16)$ \\
\hline Fludioxonil & 45 & $247>180(42)$ & $247>126(42)$ \\
\hline 3-Hydroxycarbofuran & 20 & $238>163(14)$ & $238>181(10)$ \\
\hline Imidacloprid & 15 & $256>239(8)$ & $256>89(18)$ \\
\hline Linuron & 25 & $249>160(18)$ & $249>182(16)$ \\
\hline Malathion & 20 & $331>127(12)$ & $331>99(22)$ \\
\hline Metalaxyl & 25 & $280>220(14)$ & $280>192(18)$ \\
\hline Methomyl & 17 & $163>88(8)$ & $163>106(10)$ \\
\hline Metolachlor & 25 & $284>252(14)$ & $284>176(26)$ \\
\hline Metribuzin & 33 & $215>187(18)$ & $215>131(22)$ \\
\hline Naled & 25 & $381>127(14)$ & $383>127(14)$ \\
\hline Propamocarb & 27 & $189>102(18)$ & $189>74(25)$ \\
\hline Pyraclostrobin & 25 & $388>194(12)$ & $388>163(26)$ \\
\hline Rimsulfuron & 30 & $432>182(22)$ & $432>325(14)$ \\
\hline Thiabendazole & 45 & $202>175(25)$ & $202>131(31)$ \\
\hline Thiophanate-methyl & 25 & $343>151(20)$ & $343>311(10)$ \\
\hline Triphenylphosphate & 48 & $327>77(38)$ & $327>251(26)$ \\
\hline
\end{tabular}

focussed on pesticides registered for use in Alberta. Based on a fit for purpose approach, it was decided that an average accuracy between 80 and $120 \%$ would be acceptable for both screening and confirmation of residues. The desired level of intra-day repeatability was a standard deviation of $20 \%$ or lower. Table 2 lists the average accuracies obtained for the analysis of fortified potato samples. With the exceptions of dimethoate and thiophanate-methyl, the accuracy and precision obtained for all pesticides were considered to be acceptable. It was decided that the method could be used to screen for the presence of these two pesticides however quantitation would not be considered reliable. The limit of quantitation (LOQ) was set at the lowest matrix-matched calibrator concentration $\left(5 \mu \mathrm{g} \mathrm{kg}^{-1}\right)$ for all pesticides except chlorpropham, imidacloprid, methomyl and thiophanate-methyl where the LOQ was established at $10 \mu \mathrm{g} \mathrm{kg}^{-1}$ because of inferior MS/MS response.
As an ongoing part of the method validation, one duplicate sample from each batch was selected at random and fortified with $50 \mu \mathrm{g} \mathrm{kg}^{-1}$ of each pesticide. The results of these spiked duplicate analyses are summarized in Table 2. The inter-day average accuracy obtained for all pesticides except dimethoate fell within the desired range of $80 \%-120 \%$. Inter-day precision for the various spiked duplicate samples was greater than $20 \%$ for six pesticides (carbaryl, 3-hydroxycarbofuran, methomyl, naled, thiabendazole and thiophanate-methyl). Increased variance in the precision relative to the intra-day repeatability is expected as the results of the inter-day analyses were obtained for nine different sources of potatoes rather than sets of replicate samples.

Over approximately 17 weeks in 2007, 155 samples of potatoes were purchased from 21 farmers' markets operating in the Edmonton area while 73 samples were obtained from 13 markets near Calgary. All potatoes selected for 
Table 2 Average accuracies obtained for the analysis of fortified potato samples

\begin{tabular}{|c|c|c|c|}
\hline \multirow[t]{2}{*}{ Compound } & \multicolumn{2}{|c|}{ Intra-day $\%$ accuracy $\pm \mathrm{SD}(\mathrm{n}=12$ at each level $)$} & \multirow{2}{*}{$\begin{array}{l}\text { Inter-day } \% \text { accuracy } \pm \text { SD for spiked } \\
\text { duplicates at } 50 \mathrm{~g} \mathrm{~kg}^{-1}(\mathrm{n}=9)\end{array}$} \\
\hline & $50 \mu \mathrm{g} \mathrm{kg}^{-1}$ & $300 \mu \mathrm{g} \mathrm{kg}^{-1}$ & \\
\hline Acetamiprid & $110 \pm 11$ & $105 \pm 9$ & $110 \pm 15$ \\
\hline Azinphos-methyl & $97 \pm 13$ & $99 \pm 10$ & $99 \pm 12$ \\
\hline Azoxystrobin & $104 \pm 8$ & $97 \pm 7$ & $103 \pm 10$ \\
\hline Boscalid & $97 \pm 11$ & $93 \pm 8$ & $94 \pm 10$ \\
\hline Carbaryl & $104 \pm 10$ & $106 \pm 7$ & $95 \pm 23$ \\
\hline Carbofuran & $99 \pm 11$ & $97 \pm 9$ & $104 \pm 12$ \\
\hline Chlorpropham & $95 \pm 15$ & $103 \pm 16$ & $92 \pm 18$ \\
\hline Cymoxanil & $88 \pm 11$ & $95 \pm 10$ & $112 \pm 16$ \\
\hline Diazinon & $116 \pm 9$ & $115 \pm 8$ & $98 \pm 6$ \\
\hline Dimethoate & $119 \pm 10$ & $126 \pm 13$ & $123 \pm 17$ \\
\hline Dimethomorph & $97 \pm 6$ & $95 \pm 7$ & $106 \pm 15$ \\
\hline EPTC & $98 \pm 11$ & $102 \pm 7$ & $96 \pm 10$ \\
\hline Fenamidone & $100 \pm 11$ & $97 \pm 9$ & $99 \pm 16$ \\
\hline Fluazifop-butyl & $99 \pm 9$ & $94 \pm 8$ & $106 \pm 14$ \\
\hline Fludioxonil & $114 \pm 12$ & $108 \pm 8$ & $118 \pm 19$ \\
\hline 3-Hydroxycarbofuran & $89 \pm 8$ & $96 \pm 11$ & $119 \pm 24$ \\
\hline Imidacloprid & $112 \pm 15$ & $117 \pm 10$ & $104 \pm 15$ \\
\hline Linuron & $88 \pm 10$ & $92 \pm 7$ & $99 \pm 14$ \\
\hline Malathion & $108 \pm 14$ & $107 \pm 12$ & $100 \pm 9$ \\
\hline Metalaxyl & $98 \pm 9$ & $94 \pm 6$ & $112 \pm 20$ \\
\hline Methomyl & $94 \pm 10$ & $102 \pm 12$ & $111 \pm 25$ \\
\hline Metolachlor & $101 \pm 9$ & $99 \pm 7$ & $105 \pm 13$ \\
\hline Metribuzin & $97 \pm 9$ & $95 \pm 7$ & $104 \pm 16$ \\
\hline Naled & $114 \pm 18$ & $104 \pm 10$ & $96 \pm 34$ \\
\hline Propamocarb & $103 \pm 9$ & $102 \pm 7$ & $97 \pm 15$ \\
\hline Pyraclostrobin & $107 \pm 9$ & $103 \pm 12$ & $98 \pm 13$ \\
\hline Rimsulfuron & $101 \pm 8$ & $96 \pm 6$ & $104 \pm 11$ \\
\hline Thiabendazole & $92 \pm 5$ & $88 \pm 5$ & $111 \pm 40$ \\
\hline Thiophanate-methyl & $106 \pm 37$ & $134 \pm 15$ & $103 \pm 26$ \\
\hline
\end{tabular}

$S D$ standard deviation

collection were grown in Alberta and public health authorities also recorded information regarding whether or not the potatoes were produced using certified organic farming practices. The results of the analysis of pesticide residues in fresh potatoes produced in Alberta and sold at farmers' markets are summarized in Table 3. Confirmation of pesticide identity was determined using criteria established by the European Communities (2002) based on chromatographic retention behaviour and mass spectrometric detection.

During the original analysis of the entire set of potato samples, it was observed that numerous potato samples had residues of azoxystrobin at concentrations near or below the LOQ $\left(5 \mu \mathrm{g} \mathrm{kg}^{-1}\right)$. In order to quantify these trace amounts, samples with detectable residues of azoxystrobin were reanalyzed using a lowered working analytical range of $0.5-5 \mu \mathrm{g} \mathrm{kg}^{-1}$ where only the SRM transitions of azoxystrobin and the internal standard were monitored. With a calibration curve generated using five matrix-matched standards $\left(0.5,1,2,4\right.$, and $\left.5 \mu \mathrm{g} \mathrm{kg}^{-1}\right)$, the validity of this lower range was investigated by analyzing replicate samples $(n=3)$ of each of four blank potatoes fortified with $3 \mu \mathrm{g} \mathrm{kg}^{-1}$ of azoxystrobin. Based on this set of 12 fortified replicates, the accuracy of the analysis was calculated to be $105 \%$ with a standard deviation of eight. The data shown in Table 3 for azoxystrobin were generated using the lowered working analytical range.

Chlorpropham, which is applied post-harvest to control sprouting, was the most frequently detected pesticide. It was detected in $5.7 \%$ of the potato samples tested with 
Table 3 Pesticides detected in potatoes $(n=228)$ from Alberta farmers' markets

\begin{tabular}{lcccrr}
\hline Compound & Number of detections & \multicolumn{2}{l}{ Concentration $\left(\mu \mathrm{g} \mathrm{kg}^{-1}\right)$} & \multicolumn{2}{c}{$\mathrm{MRL}^{\mathrm{a}}\left(\mu \mathrm{g} \mathrm{kg} \mathrm{kg}^{-1}\right)$} \\
\cline { 3 - 5 } & & Minimum & Median & Maximum \\
\hline Azoxystrobin & 11 & 0.6 & 1.0 & 5.1 & 30 \\
Chlorpropham & 13 & 15 & 62 & 7,600 & 15,000 \\
Imidacloprid & 8 & 15 & 20 & 31 & 300 \\
\hline
\end{tabular}

${ }^{a}$ Canadian maximum residue limit in potato (Health Canada 2010)

concentrations ranging from 15 to $7,600 \mu \mathrm{g} \mathrm{kg}^{-1}$. The current Canadian maximum residue limit (MRL) for chlorpropham in potatoes is $15,000 \mu \mathrm{g} \mathrm{kg}^{-1}$ (Health Canada 2010). The next most frequently detected pesticide was azoxystrobin which was found in $4.8 \%$ of the samples tested at concentrations between 0.6 and $5.1 \mathrm{\mu g} \mathrm{kg}^{-1}$. Azoxystrobin is used as fungicide to control plant disease in various crops including potatoes. All samples were below the Canadian MRL of $30 \mu \mathrm{g} \mathrm{kg}^{-1}$. The only other pesticide detected in the potato samples was imidacloprid which is a neonicotinoid insecticide used to control the Colorado potato beetle. Imidacloprid was detected in $3.5 \%$ of the samples at concentrations ranging from 15 to $31 \mu \mathrm{g} \mathrm{kg}^{-1}$, all of which were below the Canadian MRL of $300 \mu \mathrm{g} \mathrm{kg}^{-1}$. Only one potato sample was found to contain residues of more than one pesticide $\left(4.0 \mu \mathrm{g} \mathrm{kg}^{-1}\right.$ azoxystrobin and $180 \mu \mathrm{g} \mathrm{kg}^{-1}$ chlorpropham).

In a Canadian nationwide residue monitoring program chlorpropham was detected in 75 of 227 (33.0\%) fresh potato samples at concentrations from 10 to 14,828 $\mu \mathrm{g} \mathrm{kg}^{-1}$ (CFIA 2006). Many of the target pesticides studied in Alberta have also been included in the USDA Pesticide Data Program. Chlorpropham was detected in 563 of 744 $(75.7 \%)$ fresh potato samples analyzed at concentrations from 17 to $11,000 \mu \mathrm{g} \mathrm{kg}^{-1}$ (USDA 2009). Imidacloprid was found in 171 potato samples $(23.0 \%)$ at concentrations ranging from 2 to $49 \mu \mathrm{g} \mathrm{kg}^{-1}$ while azoxystrobin was present in 131 samples $(17.6 \%)$ at levels between 0.8 and $440 \mu \mathrm{g} \mathrm{kg}^{-1}$. Residues of boscalid and thiabendazole were present in $73(9.8 \%)$ and $54(7.3 \%)$ of the samples tested, respectively. Many of the other pesticides included in our study were not detected in fresh potatoes analyzed in the USDA monitoring program. In comparison with national pesticide residue monitoring studies carried out in Canada and the United States, the frequency and concentrations of pesticides detected in Alberta-produced potatoes were relatively low. Furthermore, none of the target pesticides were detected in 23 potato samples purchased from certified organic farming operations.

Acknowledgments The authors thank Ryan Pawsey, Elizabeth MacNeil, Angela Morrison, Ambrose Law, Elio Moreno, Lily Gu, and Svetlana Selina for the collection of samples. The technical assistance of Renata Limanowka, Desmond Tang, Joy Komarnicki, and Marlise Siegenthaler is gratefully acknowledged.

\section{References}

Alberta Agriculture and Rural Development (2010) Alberta approved farmers' markets. Available via internet. http://www1.agric.gov. ab.ca/\$Department/deptdocs.nsf/All/apa6620. Accessed 24 Jun 2010

Canadian Food Inspection Agency [CFIA] (2006) Report on pesticides, agricultural chemicals, environmental pollutants and other impurities in agri-food commodities of plant origin, fiscal year 2004/2005, vol 2. Available via internet. http://www.inspection. gc.ca/english/fssa/microchem/resid/2004-2005/plaveg_e.shtml. Accessed 24 Jun 2010

European Communities (2002) Commission decision of 12 August 2002 implementing council directive 96/23/EC concerning the performance of analytical methods and the interpretation of results, 2002/657/EC. OJ L221:8-36

Granby K, Andersen JH, Christensen HB (2004) Analysis of pesticides in fruit, vegetables and cereals using methanolic extraction and detection by liquid chromatography-tandem mass spectrometry. Anal Chim Acta 520:165-176

Health Canada (2010) List of maximum residue limits regulated under the pest control products act. Available via internet. http:// www.hc-sc.gc.ca/cps-spc/alt_formats/pdf/pest/part/protect-proteger/ food-nourriture/mrls-lmr-eng.pdf. Accessed 28 Jan 2011

Hogenboom AC, Hofman MP, Kok SJ, Niessen WMA, Brinkman UAT (2000) Determination of pesticides in vegetables using large-volume injection column liquid chromatography-electrospray tandem mass spectrometry. J Chromatogr A 892:379-390

Jansson C, Pihlstrom T, Osterdahl BG, Markides KE (2004) A new multi-residue method for analysis of pesticide residues in fruit and vegetables using liquid chromatography with tandem mass spectrometric detection. J Chromatogr A 1023:93-104

Leandro CC, Hancock P, Fussell RJ, Keely BJ (2007) Ultraperformance liquid chromatography for the determination of pesticide residues in foods by tandem quadrupole mass spectrometry with polarity switching. J Chromatogr A 1144:161-169

Liu M, Hashi Y, Song Y, Lin JM (2005) Simultaneous determination of carbamate and organophosphorus pesticides in fruits and vegetables by liquid chromatography-mass spectrometry. J Chromatogr A 1097:183-187

Okihashi M, Kitagawa Y, Akutsu K, Obana H, Hori S (2002) Determination of seventeen pesticide residues in agricultural products by LC/MS. J Food Hyg Soc Jpn 43:389-393

Ortelli D, Edder P, Corvi C (2004) Multiresidue analysis of 74 pesticides in fruits and vegetables by liquid chromatographyelectrospray-tandem mass spectrometry. Anal Chim Acta 520:33-45 
United States Department of Agriculture [USDA] (2009) Pesticide data program annual summary, calendar year 2008. Available via internet. http://www.ams.usda.gov/AMSv1.0/getfile?dDoc Name=STELPRDC5081750. Accessed 28 Jan 2011
Wang J, Chow W, Leung D (2010) Applications of LC/ESI-MS/MS and UHPLC QqTOF MS for the determination of 148 pesticides in fruits and vegetables. Anal Bioanal Chem 396:1513-1538 